\title{
The Impact of Terrorism on Brain, and Behavior: What We Know and What We Need to Know
}

\author{
Rachel Yehuda' and Steven E Hyman*,2 \\ 'Department of Psychiatry, Mt Sinai School of Medicine, New York, NY, USA; ${ }^{2}$ Department of Neurobiology, Harvard Medical School and Office \\ of the Provost, Harvard University, Cambridge, MA, USA
}

\begin{abstract}
Following the recent US experience with terrorism, including bioterrorism, significant biomedical research resources have been appropriately focused on bioterror weapons. Far less research attention has been focused on the behavioral and psychobiological effects of terrorism. Yet, the psychological responses to terrorism exert significant effects on mental and physical health and on society. We present a research agenda, based on a comprehensive review of the literature, to address the troubling gaps in our knowledge about the long-term effects of terrorism on brain, behavior, and physical health, the risk factors for predicting who will be most affected by terrorism, and interventions that might promote resilience at an individual and population level.

Neuropsychopharmacology (2005) 30, I773- 1780. doi:I0.1038/sj.npp. I3008 I7; published online I3 July 2005
\end{abstract}

Keywords: terrorism; bioterrorism; post-traumatic stress disorder

Terrorism is about psychology... It is about making ordinary people feel vulnerable, anxious, confused, uncertain, and helpless (Philip Zimbardo, 2003).

\section{INTRODUCTION}

In the wake of the events of September 11, 2001, and the subsequent anthrax bioterror attacks, much research has appropriately been focused on bioterror weapons, including diagnostics, drugs, and vaccines; far less research attention has been focused on the behavioral and psychobiological effects of terrorism. However, as the broad goals of terrorism are ultimately psychological, affecting entire populations well beyond the scope of physical destruction of terrorist acts, this relative neglect will undermine the government's efforts to provide true protection to its citizens from the deleterious consequences of terrorism.

It has now become clear that psychological responses following terrifying events have wide-ranging implications

A white paper from the interdisciplinary task force on terrorism of the American College of Neuropsychopharmacology (ACNP) based on papers presented by Paul Slovic, Rachel Yehuda, Edna Foa, Daniel Pine, Matthew Friedman, John Krystal, and Robert Ursano at the ACNP annual meeting December 2003.

* Correspondence: Dr SE Hyman, Office of the Provost, Harvard University, Massachusetts Hall, Cambridge, MA 02138, USA, Tel: + I 617496 5100, Fax: + I 6174964630 ,

E-mail: steven_hyman@harvard.edu

Received I October 2004; revised 5 May 2005; accepted 27 May 2005 Online publication: 2 June 2005 at http://www.acnp.org/citations/ Npp060205040464/default.pdf on both mental and physical health. Yet, there are troubling gaps in our knowledge about the long-term effects of terrorism on brain, behavior, and physical health, the risk factors for predicting who will be most affected by terrorism, and interventions that might promote resilience at an individual and population level. This information is essential in curtailing damage done by terrorists to the psyche of our nation.

We present a research agenda based on a comprehensive review of the literature, aimed at highlighting the information necessary for insuring maximal preparedness to future terrorist threats and events. We implicitly suggest that research on the behavioral and psychobiological responses to terrorism requires financial support and the enlistment of capable scientists prior to the next attack, but more importantly, it necessitates that scientists and the policy makers reach agreements prior to the next attack, that would permit researchers access to people affected by terrorism as soon after events as it is safe to do so. Indeed, much of why we have such limited information at the present time results from a failure to properly conduct research in the aftermath of prior terrorist events. Although we understand that following the Oklahoma City bombing and the attacks on the World Trade Center, the reluctance to permit research early on was prompted by compassion for the victims and a desire to not interfere with logistics, at the same time as victims were being 'protected' from scientists, unproved therapeutic interventions were administered. It is important that the research and the disaster response communities reach accommodations to permit research in the immediate aftermath of terrorism or we may never know the best ways to respond acutely or to identify 
early those individuals who will need intensive interventions. The role of research after terrorism should be no different from what it is in other forms of human adversity for which we need to find appropriate interventions.

\section{BROAD POPULATION RESPONSES TO TERRORISM}

\section{Risk Perception and Management}

Following the terrorist attacks of September 11, 2001, a majority of Americans reported symptoms such as difficulties paying attention at work or school, depressed feelings, disrupted sleep, and anger (Pew Research Center, 2001). The government's response consisted of taking action to alter many routines of life in the spirit of protecting the population from subsequent attack. Presumably, such actions should have also served to alleviate distress and anxiety among the population. However, it is not at all clear what the impact of this governmental response was with respect to increasing or decreasing psychological distress among the population. Furthermore, no research was conducted to determine whether alternative responses by the government could have alleviated fears while increasing personal alertness to potential threats.

In reality, extraordinary steps were taken that dramatically altered the lives of all Americans, without giving citizens a proper idea of the probability involved in being the target of subsequent attack. A major gap in the US response to terrorism in this regard concerns the lack of understanding of the factors that influence the perception of risk in order to promote effective communication and adaptive responses to the threat of terrorism among its citizens. Understanding the role of emotional processing, especially when information for a rational analysis is incomplete, is critical to this process, as terrorism intentionally hits emotional 'risk perception hot buttons', resulting in a very different type of risk assessment than other potentially dangerous events. Recent developments in the field of neuroscience have helped elucidate how emotional responses to threats such as terrorism result in a series of powerful physiological and behavioral responses to danger (see Box 1). However, what now needs to be understood is how to intervene such that rational information can be integrated while emotions are activated, in order to allow individuals who are experiencing fear, to nonetheless know they are safe, or to take appropriate steps to increase their personal safety.

In this vein, it is important to note that the response to terrorism poses a unique challenge in contradicting the normal phenomenon of 'optimism bias' (Weinstein, 1989), in which persons usually underestimate the extent of personal risk to life events. It is critical to understand why terrorism fails to elicit optimism bias (Klar et al, 2002), and how it promotes, instead, a distortion of logical thinking called 'probability neglect' (Rottenstreich and Hsee, 2001), which can contribute to over-reactions and unnecessary alterations in behavior. An understanding of such cognitive distortions will allow the government to implement better strategies for preparedness and risk communication.

\section{Managing a Chronic State of Heightened Vigilance}

While it is essential that the information presented by the government to increase preparedness not result in undue fear and panic, it is also critical to understand the factors that allow messages about preparedness to be well attended to in order to avoid both a lack of sustained attention and vigilance to an ongoing threat, and casualties based on the lack of preparedness. For example, data collected on emergency admissions during the first hours after SCUD missile attacks in Israel demonstrate that the cause of the vast majority of admission (825 of 1059) could not be attributed directly to damage caused by the missiles, but rather, lack of preparedness. Many came for help after false alarms. Of those who died or were injured, most suffocated by gas masks that were worn with their airtight caps on; were hurt while rushing to safety; or when needlessly injected themselves with atropine; and many were admitted with acute stress reactions. These figures show the toll of fear and lack of preparedness (prompted by a governmental concern to not distribute masks in a timely manner or instruct the population to unpack or practice with the safety

Box I Fear, Anxiety, and the Brain

The term 'emotion' is used in common parlance to refer to subjective feelings, but these feelings represent an integrated set of responses to stimuli that have significance with respect to survival. Emotions regulate physiologic responses within the body, activate behavioral response patterns, and alter levels of arousal and vigilance - as well as producing subjective feelings. Fear prepares us to cope with threat and danger (Lang et al, 2000). It does so by shifting the balance in the nervous system (permitting the 'sympathetic nervous system to dominate') preparing the body to fight or flee. 'Stress hormones' are released including adrenaline (epinephrine) and cortisol that alter the body's metabolism to make energy available, and generally prepare the body for an emergency. Fear also actives brain systems that produce rapid and stereotyped defensive behaviors, sharpen perception, and prepare memory circuitry to record the circumstances in which the danger has been experience so that it can be avoided in the future. The key brain structure that organizes the response to danger is called the amygdala; this is an evolutionarily old structure found deep in temporal lobes of our brains.

Fear is usually a transient, adaptive response to an identifiable threat. In contrast, anxiety represents a longer-term response to impending danger, which may range from a well-defined circumstance to situations that are very vague. In some cases, anxiety may not be associated with a single stimulus, but may result from an accumulation of perceived cues. Anxiety is marked by apprehension, vigilance, negative thoughts and feelings (eg worry), motor tension, and physiologic arousal. As anxiety represents a state of preparedness for a potential threat, and many situations lack clear safety signals, the time course of anxiety may be quite protracted. Fear and anxiety help us cope with danger in the short run, but when they persist, they can have serious negative consequences for general health and mental functioning.

Our knowledge of how fear and anxiety operate within the brain creates significant opportunities to develop strategies for treating fear and stress-related disorders including PTSD. This knowledge can also be used to develop markers (perhaps using brain imaging) to guide research in developing new diagnostic methods and new treatments for anxiety disorders. 
kits to avoid the psychological impact of mass apprehension and panic) (Carmeli et al, 1992).

\section{Risk Communication in Special, High-Risk Groups}

While most terrorist attacks do not cause extensive loss of life, the psychological impact of terrorist acts and threats can be widespread. While the reactions of the general public can range from mild to moderate after an adjustment period (Ayalon and Lahad, 2000; Hobfoll et al, 1991; Galea et al, 2002; Silver et al, 2002), it is important to understand and prevent extreme and dangerous responses in a minority that may include transient panic, retaliatory attacks on local minority groups, nonadherence to medical or other recommendations, and actions that have major economic impact (eg decreased air travel). Partly, these responses can be reactions to information that is sensationalized through the media or poor implementation of evidence-based approaches to communication by public officials.

Research can help the government identify the kind of social and psychological threats most likely to be faced in the aftermath of terrorism and how to communicate risks to the public in a manner that provides a balance between recognition of danger and creation of undue fear and psychological stress. The recent Institute of Medicine report (2003): Preparing for the Psychological Consequences of Terrorism: A Public Health Strategy carefully considers the three phases of terrorist attacks: preevent, event, and postevent. Since careful preparation is a critically important response to terrorism, emphasis should be placed on research that could be used to guide public officials and the media in developing public education and risk communication strategies that serve the public health. Such strategies might reasonably be targeted to the alterable factors identified in the risk perception research alluded to above, such as controllability, actual exposure risk, degree to which lethal consequences can be averted, novelty, and the like (Weisaeth, 1994; Zimbardo et al, 1977; McQuire, 1964). As an example of such efforts, researchers can design test messages and programs to see if they are working as intended (Fischhoff, 2002). The public should be informed about specific actions they can take to reduce risk. These must be valid and clearly communicated, unlike some recent warnings that people found almost surreal (seal your home with duct tape) or contradictory (stay in your home in the event of a radiological incident, yet get as far away from the source as you can). Such an ongoing scientificmedia partnership should be planned in advance of any crisis.

\section{TERRORISM AND THE RISK OF PSYCHOPATHOLOGY AND DISABILITY}

\section{What is a Pathologic Response?}

In the days following 9/11, the majority of people in the US reported problems sleeping and concentrating, irritability, nightmares, distressing thoughts about the event, or distress at reminders of the event (Schuster et al, 2001), but 5-8 weeks after the attacks, most had recovered from initial symptoms (Galea et al, 2002). The important question raised by these findings is whether the initial symptoms observed constituted a clinical syndrome requiring treatment, or was rather, a reflection of normal acute, transient distress not requiring intervention.

\section{Predictors and Possible Mechanisms of Chronic Post-Traumatic Stress Disorder (PTSD): Can Pathologic Responses be Identified Early?}

A major gap in our knowledge is the inability to predict who will develop chronic, long-term symptoms based on initial responses to trauma. As reviewed by Yehuda (1999, 2002), researchers have attempted to identify symptoms that might predict subsequent psychopathology, primarily PTSD, such as, intrusive thoughts, dissociation from reality during the experience, avoidance, and hyperarousal within several days following a traumatic event. However, none of these has convincingly been identified as a clinically useful predictor. Thus, the search for predictors of later psychopathology based on early symptoms in response to terrorism remains an important research question. Increasing attention has been focused on biologic predictors of psychopathology, yet, in view of the fact that only a proportion of those exposed to terrorism develop long-term symptoms, investigators are now wondering whether it is appropriate to search for abnormalities in the 'normal stress response'.

Indeed, basic research on consolidation of memories, that is, processes that convert short- into long-term memories, (Box 2) has demonstrated that release of the stress hormones, adrenaline (epinephrine) and noradrenaline (norepinephrine) from the adrenal gland and sympathetic nervous system, can promote the consolidation and later retrieval of memories encoded at times of strong emotion (Cahill et al, 1994). High levels of stress hormones that may occur in some individuals during trauma might strengthen traumatic memories and increase the probability of intrusive recollections (Pitman, 1989; Yehuda, 2002). If true, it might be optimal to provide early pharmacologic interventions to trauma-exposed subjects, but this suggestion must be implemented cautiously in view of how many persons spontaneously recover from the effects of terrorism. These considerations point to a need to better understand the interactions of physiologic and experiential factors at the time of a traumatic event.

\section{Risk Factors for Chronic Psychopathology}

Whereas the typical public health approach to terrorism would focus on the impact of this event on the majority of persons exposed, the literature is clear that only a proportion of persons exposed to any given traumatic event suffer long-term symptoms. These findings raise the question of what factors mediate risk and resilience. On the basis of retrospective studies, those at greatest risk for developing PTSD following a traumatic event are persons with a family history of mental illness (Breslau et al, 1991), prior exposure to trauma (Nishith et al, 2000, Breslau et al, 1999), less cognitive capacity (Silva et al, 2000), female gender (Breslau et al, 1999), and certain pre-existing personality traits such as proneness to experiencing negative emotions and having poor social supports (Brewin et al, 2002). To some extent, prospective studies have supported these findings, in that persons showing less 
Box 2 The Memory of Terror: Stress-Induced Disturbances in Memory

Emotionally arousing experiences create long-lasting memories. This is generally adaptive, as it means that a single experience with danger can produce memories that might permit the danger to be avoided in the future. Accompanying conscious memories are rapid physiological responses to cues that are reminiscent of the danger; these prepare the body to respond if the danger cannot be avoided. In most cases, individuals can regulate the amount of distress that is associated with a traumatic memory. In PTSD, individuals experience intense distress and arousal when confronted with the memory of an event. However, PTSD occurs in the minority of those exposed to the traumatic event, raising the question of why distress and intrusive memories are only present in some trauma survivors.

Results of prior neuroendocrine studies in PTSD, in tandem with recent observations regarding biological alterations in the acute aftermath of trauma and their association with the subsequent development of PTSD, have suggested that PTSD may occur because of a failure to contain the normal stress response at the time of the trauma, resulting in intrusive, avoidance, and hyperarousal symptoms (Yehuda, 2002). The normal fear response is characterized by a series of reactions that help the body cope with stress. Activation of the sympathetic nervous system (SNS) and the release of adrenaline allow the organism to increase its physiological capacity for 'fight-or-flight' in response to threat (Cannon, 19/4) and facilitate consolidation of the threat memory. The simultaneous activation of the hypothalamicpituitary-adrenal (HPA) axis, culminating in the release of cortisol, helps contain the stress response when the threat is removed (Munck et al, 1984). Preliminary findings (Resnick et al, 1995; Delahanty et al, 2003) suggest that individuals who develop PTSD have attenuated cortisol responses to trauma, and may thus fail to limit the SNS response. This could result in persistently increased levels of catecholamines at the time during which the memory of the traumatic event was undergoing consolidation. Therefore, the memory of the event would not only be strongly encoded, but associated with extreme subjective distress (Pitman, 1989), If low cortisol levels represent a pre-existing characteristic, re-enforced by 'overconsolidation' at the time of the trauma, then similarly failing to properly contain the SNS response to traumatic reminders could perpetuate the intrusive and hyperarousal symptoms of PTSD, leading to the elaboration of avoidance symptoms that commonly occurs in the disorder.

Novel treatment strategies may involve administration of a $\beta$-adrenergic blocker (a drugs that block the effects of adrenaline on its $\beta$-adrenergic receptors), such as propranolol, which might prevent the enhancing effects of emotional arousal on long-term memory in human subjects (Cahill et al, 1994), or the administration of glucocorticoids (Schelling et al, 2004), which has recently been found to prevent the development of traumatic memories and PTSD. Increased understanding of basic brain processes is likely to lead to new treatments for disorders resulting from traumatic experiences.

\section{Box 3 Genetics of Risk for PTSD}

As with essentially all illnesses, individuals have different levels of risk for developing severe psychological sequelae to trauma, partly dependent on their genes. The role of genes in any trait, including risk of an illness, can be studied by comparing identical twins (who share 100\% of their DNA) with fraternal twins (who share on average $50 \%$ of their DNA). Assuming that the family environment is the same whether a twin pair is identical or fraternal, then major differences are likely due to genes. Since identical twins are nearly genetically identical, if genes matter for a trait, they should be more like each other on average than fraternal twins. Twin studies suggest that genes play an important role in vulnerability to PTSD and other anxiety disorders, but not the entire role. The overall result of studies to date is that risk is the product of multiple genes and nongenetic factors working together. A major research goal is to find the precise genes involved in risk of PTSD and other anxiety disorders. The major purpose of this research is predicated on the hope that risk genes will point researchers toward modifiable pathways in the brain that can be used to produce better treatments. Scientists are also interested in finding genes that promote resilience.

In addition to twin studies, there are other types of studies that are being used to tease out the roles of different genetic and environmental risk factors. One recent study of depression is a good illustration of a useful methodology that could also be applied to anxiety disorders. A birth cohort in New Zealand was followed over time and examined at regular intervals into their mid-20s (Caspi et al, 2003). A particular variation in the DNA that controls levels of expression of a critical brain protein, the serotonin transporter, was found to moderate the influence of stressful life events on depression. Individuals with a shorter version of this DNA segment, who also experienced stressful life events, had an elevated risk of depression. The short DNA segment alone or stressful experience in the absence of the DNA variant did not elevate risk. Such findings require independent replication, but potentially provide a powerful example of a gene-environment interaction of the sort that would be relevant to PTSD as well.

recovery tended to have more of these risk factors than those who did not. However, when such risk factors have been used in attempts to predict PTSD in prospective studies, no single variable emerged as a significant predictor. Thus, a major gap in our knowledge concerns how to use risk factors in the prediction of PTSD in specific individuals or populations.

The evidence that family history contributes to risk raises the question of whether the familial contribution is due to shared genes, shared environment, or an interaction of the two (Box 3). Adult children of Holocaust survivors with PTSD show a greater prevalence of PTSD themselves following trauma, compared to adult children of Holocaust survivors without PTSD (Yehuda et al, 1998). Evidence that family resemblance with respect to PTSD may be at least partly explained by genes comes from twin studies (Goldberg et al, 1990) (Box 3). Overall, we need a better understanding of the influence of risk factors such as genetics, history of childhood trauma, low educational attainment, personal or family history of anxiety or mood disorders, recent history of heavy alcohol or drug use, and poor social supports. To the extent that risk factors are important in the prediction of subsequent mental health problems following terrorism, this calls into question the current mental health approach of delivering immediate, short-term interventions to the masses exposed, and suggests that it is more prudent to deliver more focused interventions to the minority of those at risk.

\section{The Relationship between Short-Term Normal Responses and Long-Term Psychopathology}

It is not clear whether and to what extent pretraumatic risk factors influence the intensity of the response to trauma, but presumably, these risk factors are more relevant in situations where the 'dose' of trauma is less extreme, that is, a situation from which a person at lower risk might recover. Clarifying the causes of immediate and long-term symptoms will lead to ideas about potential preventative treatments.

In the case of terrorism, it may be necessary to amend some ideas about how long symptoms should last before 
they are considered pathological, and to consider prophylactic interventions very carefully in light of the specific features of terrorism. That is, although longitudinal studies have demonstrated that a key research variable in considering pathological outcomes following terrorist acts is the passage of time, a terrorist act usually initiates anticipatory anxiety about further attacks. If a terrorist event represents the beginning or continuation of a situation or threat - as it often does - the timetable for recovery may be shifted. Thus, asking the degree to which the effects of terrorism produce a pathological outcome, it is appropriate to reconsider the time period for which initial symptoms are considered normal responses, depending on the time course of the threat, its reporting in the media, and the timing of official government warnings.

\section{THE EFFECTS OF TERRORISM ON CHILDREN}

\section{Stress, Trauma, and Psychopathology in Children}

Society is appropriately concerned about the impact of terrorism on children, but there are few relevant studies. What has emerged as the most interesting aspect of this research, however, is that whereas for adults, pretraumatic risk factors are extremely important predictors of chronic post-traumatic symptoms, for children, the most important consideration appears to be the severity of the traumatic event and developmental stage. Understanding the differences between post-traumatic mental health consequences of terrorism in adults $v s$ children is absolutely essential to developing appropriate intervention strategies, since terrorism effects both young and old.

In addition to the 'dose' or degree of exposure to the event, the amount of family support available during the experience and in the aftermath of trauma, the amount of life disruption, and the degree of social disorganization are important predictors of mental health symptoms. Much of our knowledge of the psychological effects on children of war or terrorism comes from research on various events occurring since World War II. Examples include the Holocaust (Sagi-Schwartz et al, 2003), the Belfast riots in Northern Ireland (Lyons, 1979), the Iraqi occupation of Kuwait (Hadi and Llabre, 1998), the ethnic rivalry in Sri Lanka (Chase et al, 1999), the effects of the current situation in the Middle East (Thabet and Vostanis, 1999), and ethnic cleansing in Cambodia, Rwanda and Bosnia (Mollica et al, 1997; Monk et al, 2003) and Bosnia. These studies find that only in a minority of cases will children develop chronic psychopathology (Pine and Cohen, 2002). Nonetheless, what is striking is the differences between children and adults with respect to the centrality of trauma exposure as a direct cause of symptoms. Certainly in adults, pre- and posttraumatic risk factors are emphasized far more as predictors of symptoms, raising the question of whether the biologic responses to trauma in younger persons is different than in older ones. Furthermore, in view of the fact that prior trauma exposure is a potent risk factor for psychopathology in response to a subsequent traumatic exposure, it may be that the real consequences of terrorism in children is to create a basis for risk for psychopathology in response to subsequent trauma exposure.

\section{Terrorism Risk and Interventions: a Developmental Framework}

In terms of treatment of children, an important concern that arises is whether and to what extent interventions developed for adults post-trauma can be utilized in children. Most psychotherapeutic approaches use some form of cognitive behavioral therapy (CBT), and children have cognitive abilities. It is clear, however, that some form of cognitive capacity is necessary for developing post-traumatic psychopathology. Infants, for example, are protected from full psychological 'exposure' to terrorism by their cognitive immaturity; most adolescents, on the other hand, are capable of apprehending the full horror of such events. Yet, infants will be highly vulnerable to degradation of caregiver function as they are totally dependent on adult care. After children form attachments to caregivers, they are highly sensitive to separation and loss, particularly if frightened. Children gauge threats based on caregiver responses. Since terrified parents are terrifying to children, parents can moderate or mediate the propagation of terror as a vector for the spread of fear to children. Calm and functional parents, teachers, and other adults can reassure children. In addition, it is not clear whether the same pharmacologic agents used for post-trauma syndromes in adults should be used in children. A major gap in our knowledge is that there is virtually no research that has examined the effectiveness of any intervention for children following large-scale disasters or terrorism. This should be a high priority.

\section{INTERVENTIONS FOLLOWING TERRORIST ACTS}

There is very little empirical knowledge about interventions following terrorism and no available empirical knowledge about interventions following bioterrorism. On the other hand, much is known about interventions for acute and chronic stress reactions following other types of traumatic events (eg rape, war, accidents). The gap in our knowledge, however, is the extent to which the interventions that have been demonstrated to be efficacious for other traumatic events are useful and/or practical in the aftermath of terrorism, and if so, to whom should these interventions optimally be offered.

Research to date has focused on two types of interventions to be administered shortly after a traumatic event that have the goal of preventing chronic stress reactions: psychological debriefing, especially Critical Incident Stress Debriefing (CISD; Mitchell, 1983), and brief CBT. These differ in several regards, but most significantly debriefing is administered to all exposed individuals and CBT only to those exhibiting symptoms. There is also early work on the use of drugs such as propranolol (Pitman et al, 2002) to block the action of stress hormones in the consolidation of traumatic memories, or cortisol (Schelling et al, 2004) (see Box 2), but large-scale trials of efficacy have not yet been performed.

While many who receive debriefing describe it as helpful (eg Carlier et al, 2000), in view of how expensive it can be to deliver even single sessions of debriefing to thousands of persons who can potentially be exposed to a terrorist event, the critical question becomes one of whether debriefed 
individuals subsequently exhibit less post-traumatic psychopathology than do nondebriefed individuals. The study providing the strongest support for debriefing (Wee et al, 1999) was based on a PTSD symptom questionnaire completed by emergency medical service workers comparing those who did $v s$ those who did not receive the intervention. However, the absence of random assignment and preintervention assessment of symptoms limit the conclusion that can be drawn from the study. Other studies suffer methodological shortcomings, or have not used critical incidence debriefing in the aftermath of a terrorist attack, making it difficult to conclude that this should be the intervention of choice. In light of the lack of information available, it is of some concern that FEMA utilizes debriefing in the absence of corroborating evidence that it prevents longer-term symptoms, particularly since data from two randomized clinical trials suggest that debriefing may even impede natural recovery from trauma (although these were not studies of the aftermath of terrorism) (Bisson et al, 1997; Mayou et al, 2000).

How might debriefing worsen mental health outcomes? In the aftermath of trauma, extreme fear reactions are likely to be associated with increased levels of adrenaline and noradrenaline. Current neuroscience research (Box 2) raises the hypothesis that 'retelling' in the hours immediately following a traumatic experience, especially if strong emotional responses are encouraged, might lead to greater consolidation of traumatic memories. In light of the clinical trials findings, debriefing requires more systematic study prior to its implementation as a component of disaster policy.

Promising interventions include brief CBT involving four to five sessions starting 2-5 weeks after the traumatic event. Yet, data on the efficacy of this treatment for survivors of terrorism have not been published. Thus, priorities for future research include to identifying the minimum treatment necessary to successfully prevent chronic PTSD and related problems and examining the optimum circumstances (eg time elapsed since the trauma, who is most likely to benefit) for providing the interventions. It is further necessary to validate the efficacy of interventions with a wider range of trauma populations including victims of terrorist attacks in countries where terrorism is prevalent.

\section{POPULATION LEVEL ISSUES: COMMUNICATION}

The promotion of societal/community resilience is best achieved before a terrorist attack. Therefore, an ongoing scientific-media partnerships is crucial to the achievement of such a goal.

However, such communications must take into account the challenges in delivering educational messages about public health prevention and intervention to a heterogeneous group of citizens. To achieve this, it is necessary to study the impact of different types of informational messages, in relation to how these messages are delivered and by whom.

To date, information on the effect of media reporting on distress experienced by the general population is poorly understood. It is also unclear whether use of the media provides the best vehicle for public information (US
Department of Health and Human Services, 2002). Experience in New York City following the September 11th attacks demonstrates that media exposure exacerbates distress in high-risk populations, but attenuates distress more broadly (Schuster et al, 2001; Schlenger et al, 2002).

An emerging but scant empirical and clinical literature on the relationship between televised news consumption and distress reveals different results for children and adults as well as different results for those directly and indirectly affected by terrorism. In short, among those adults who directly experienced loss or witnessed a terrorist event, there exists a dose-response relationship between posttraumatic distress and exposure to televised terrorismrelated material (Schuster et al, 2001; Schlenger et al, 2002), whereas this dose relationship does not appear among those adults not directly affected by terrorism (Ahern et al, 2002). It does appear, however, that news consumption is related to temporary increases in anxiety in the general adult public. Children, however, appear to be equally affected by news coverage, regardless of the extent of their involvement in the disaster (Pfefferbaum et al, 2001).

Interpretation of these findings is complicated because there may be differences in patterns of television viewing. Those most likely to already be distressed may watch the most television, possibly as a coping mechanism to better understand the event (Schlenger et al, 2002). There is also the possibility of a reporting bias (or memory or attention bias) such that those who endorse more distress may also endorse more exposure to media coverage.

It is critical to understand the impact of the media on the population and meet the challenges of using the media to promote positive messages that promote resilience. This step requires systematic investigation. It is also important to investigate the possibility of a role for media as a means of helping citizens regulate post-traumatic anxiety and arousal. As days go by, information about abnormal reactions and where to get help might also be aired so that viewers can make accurate assessments of their own (or a loved one's) psychological state. In this way, vulnerable individuals might be self-identified as soon as possible and directed to appropriate professional assistance.

\section{MAJOR CONCLUSIONS: WHAT WE KNOW AND WHAT WE NEED TO KNOW}

\section{ACNP Task Force on Terrorism}

What we know:

1. Terrorist acts produce devastating injuries, destruction, and death. However, their ultimate goal is psychological: to create a climate of fear, uncertainty, and vulnerability. The psychological effects of terrorism are central to the political goals of the perpetrators.

2. Psychological effects exert strong and persistent effects on important neurobiologic systems. This is why a neurobiologic perspective is essential to the development of knowledge about the effects of terrorism.

3. Following a terrorist attack, persons will be fearful, anxious, and distressed for a few weeks to months - but the vast majority will prove resilient. 
4. A significant minority of those affected by terrorism will need mental health treatment because they develop longterm and disabling disorders, most notably PTSD. Others may develop depression or increase their use of alcohol or other addictive drugs. For this subgroup, the resource utilization will be very high.

5. The risk of developing a long-term mental illness is based on two interacting factors: (1) the directness and severity of a person's exposure to the terrorist event and (2) the degree of personal susceptibility. The more directly a person is affected by a terrorist act, the greater is the risk of developing post-traumatic psychopathology. However, research shows that some people are more susceptible than others because of genetic differences, as well as other factors (eg prior history of traumatization).

\section{Gaps in our knowledge:}

1. Research is needed to identify who needs emergency mental health services, and what those services should consist of.

2. Research is needed to develop interventions that promote resilience and prevent the onset of traumarelated disorders.

3. Research is needed to examine the practice of debriefing or other mental health interventions in the immediate aftermath of trauma.

4. Research is needed to develop age-appropriate interventions that prevent the onset of chronic mental disorders in children as a result of terrorist acts or ongoing terrorist threats.

\section{RECOMMENDATIONS: WHAT WE MUST DO NOW}

1. We urge greater investment in research to identify those at risk for chronic psychopathology in response and to help prevent onset of trauma-related disorders, especially in children.

2. Research is needed to determine the long-term effects of terrorism on the brain, behavior and on physical health, and to understand how the effects of terrorism might differ from other disasters, especially when the threat continues over time.

3. We must find new ways to make research easier to perform soon after a terrorist attack-or we will never learn what we need to know. We will never discover ways to identify who is at greatest risk, what interventions will prevent them from developing long-term disorders, and when those interventions should be given.

4. We must make sure that research findings are incorporated more rapidly into disaster planning.

\section{REFERENCES}

Ahern J, Galea S, Resnick HS, Kilpatrick DG, Bucuvalas M, Gold J et al (2002). Television images and psychological symptoms after the September 11 terrorist attacks. Psychiatry 65: 289-300.

Ayalon O, Lahad M (2000). Life on the Edge, Coping with War, Terror and Violence. Nord Publications: Haifa (Hebrew).
Bisson JI, Jenkins PL, Alexander J, Bannister C (1997). Randomised controlled trial of psychological debriefing for victims of acute burn trauma. Br J Psychiatry 171: 78-81.

Breslau N, Chilcoat HD, Kessler RC, Davis G (1999). Previous exposure to trauma and PTSD effects of subsequent trauma: results from the Detroit Area Survey of Trauma. Am J Psychiatry 156: $902-907$.

Breslau N, Davis GC, Andreski P, Peterson E (1991). Traumatic events and posttraumatic stress disorder in an urban population of young adults. Arch Gen Psychiatry 48: 216-222.

Brewin CR, Rose S, Andrews B, Green J, Tata P, McEvedy C et al (2002). Brief screening instrument for post-traumatic stress disorder. Br J Psychiatry 181: 158-162.

Cahill L, Prins B, Weber M, McGaugh JL (1994). $\beta$-Adrenergic activation and memory for emotional events. Nature 371: 702-704.

Cannon WB (1914). Emergency function of the adrenal medulla in pain and the major emotions. Am J Physiol 3: 356-372.

Carlier IVE, Voerman AE, Gersons BPR (2000). The influence of occupational debriefing on post-traumatic stress symptomatology in traumatized police officers. Br J Med Psychol 73: 87-98.

Carmeli A, Mevorach L, Leiberman N, Taubman A, Kahnovitz S, Navon D (1992). The Gulf War: the home front in a test of crisis Final Report, Department of Behavioral Sciences, Israel Defense Forces.

Caspi A, Sugden K, Moffitt TE, Taylor A, Craig IW, Harrington H (2003). Influence of life stress on depression: moderation by a polymorphism in the 5-HTT gene. Science 301: 386-389.

Chase R, Doney A, Sivayogan S, Ariyaratne V, Satkunanayagam P, Swaminathan A (1999). Mental health initiatives as peace initiatives in Sri Lankan schoolchildren affected by armed conflict. Med Conflict Survival 15: 379-390.

Delahanty DL, Raimonde AJ, Spoonster E, Cullado M (2003). Injury severity, prior trauma history, urinary cortisol levels, and acute PTSD in motor vehicle accident victims. J Anxiety Disord 17: $149-164$

Fischhoff B (2002). Assessing and communicating the risks of terrorism. In: Teich AH, Nelson SD, Lita SJ (eds). Science and Technology in a Vulnerable World. AAAS: Washington.

Galea S, Ahern J, Resnick H, Kilpratric D, Bucuvalas M, Gold J et al (2002). Psychological sequelae of the September 11 terrorist attacks. N Engl J Med 346: 982-987.

Goldberg J, True WR, Eisen SA, Henderson WG (1990). A twin study of the effects of the Vietnam War on posttraumatic stress disorder. JAMA 263: 1227-1232.

Hadi F, Llabre M (1998). The Gulf crisis experience of Kuwaiti children: Psychological and cognitive factors. J Trauma Stress 11: 45-56.

Hobfoll SE, Spielberger CD, Breznitz S, Figley C, Folkman S, Green BL (1991). War-related stress: addressing the stress of war and other traumatic events. Am Psychol 46: 848-855.

Institute of Medicine (2003). Preparing for the Psychological Consequences of Terrorism: A Public Health Strategy. The National Academic Press: Washington, DC.

Klar Y, Zakay D, Sharvit K (2002). 'If I don't get blown up...': realism in face of terrorism in an Israeli nationwide sample. Risk Decis Policy 7: 203-219.

Lang PJ, Davis M, Ohman A (2000). Fear and anxiety: animal models and human cognitive psychophysiology. J Affect Disord 61: 137-159.

Lyons H (1979). Civil violence-the psychological aspects. J Psychosom Res 23: 373-393.

Mayou RA, Ehlers A, Hobbs M (2000). Psychological debriefing for road traffic accidents: three-year follow-up of a randomised controlled trial. Br J Psychiatry 176: 589-593.

McQuire WJ (1964). Inducing resistance to persuasion: some contemporary approaches. In: Berkowitz L (ed). Advances in Experimental Social Psychology. Academic Press: New York. 
Mitchell JT (1983). When disaster strikes... The Critical Incident Stress Debriefing process. J Emerg Med Serv 8: 36-39.

Mollica R, Poole C, Son L, Murray C, Tor S (1997). Effects of war trauma on Cambodian refugee adolescents' functional health and mental health status. J Am Acad Child Adolesc Psychiatry 36: 1098-1106.

Monk C, McClure EB, Nelson EB, Zarahn E, Bilder RM, Leibenluft $\mathrm{E}$ et al (2003). Adolescent immaturity in attention-related brain engagement to emotional facial expressions. Neuroimage 20: 420-428.

Munck A, Guyre PM, Holbrook NJ (1984). Physiological functions of glucocorticoids in stress and their relation to pharmacological actions. Endocr Rev 93: 9779-9783.

Nishith P, Mechanic MB, Resick PA (2000). Prior interpersonal trauma: the contribution to current PTSD symptoms in female rape victims. J Abnormal Psychol 109: 20-25.

Pew Research Center (2001). American psyche reeling from terror attacks. http://people-press.org/reports/display.php3?ReportID $=3$.

Pfefferbaum B, Nixon S, Tivis R, Doughty D, Pynoos R, Gurwitch R et al (2001). Television exposure in children after a terrorist incident. Psychiatry 64: 202-211.

Pine DS, Cohen JA (2002). Trauma in children and adolescents: risk and treatment of psychiatric sequelae. Biol Psychiatry 51: 519-531.

Pitman RK (1989). Post-traumatic stress disorder, hormones, and memory. Biol Psychiatry 26: 221-223.

Pitman RK, Sanders KM, Zusman RM, Healy AR, Cheema F, Lasko NB et al (2002). Pilot study of secondary prevention of posttraumatic stress disorder with propranolol. Biol Psychiatry 51: 189-192.

Resnick HS, Yehuda R, Foy DW, Pitman R (1995). Effect of prior trauma on acute hormonal response to rape. Am J Psychiatry 152: $1675-1677$.

Rottenstreich Y, Hsee CK (2001). Money, kisses, and electric shocks: on the affective psychology of risk. Psychol Sci 12: 185-190.

Sagi-Schwartz A, van Ijzendoorn M, Grossmann K, Joels T, Grossmann K, Scharf M et al (2003). Attachment and traumatic stress in female Holocaust child survivors and their daughters. Am J Psychiatry 160: 1086-1082.

Schelling G, Kilger E, Roozendaal B, de Quervain DJ, Briegel J, Dagge A et al (2004). Stress doses of hydrocortisone, traumatic memories, and symptoms of posttraumatic stress disorder in patients after cardiac surgery: a randomized study. Biol Psychiatry 55: 627-633.

Schlenger WE, Caddell JM, Ebert L, Jordan BK, Rouke KM, Wilson $\mathrm{D}$ et al (2002). Psychological reactions to terrorist attacks: findings from the national study of American's reactions to September 11. JAMA 288: 581-588.

Schuster M, Bradley D, Stein M, Jaycox LH, Collins RL, Marshall GN et al (2001). A national survey of stress reactions after the September 11, 2001, terrorist attacks. $N$ Engl J Med 345: $1507-1512$.

Silva RR, Alpert M, Munoz DM, Singh S, Matzner F, Dummitt S (2000). Stress and vulnerability to posttraumatic stress disorder in children and adolescents. Am J Psychiatry 157: 12291235.

Silver RC, Holman EA, McIntosh DN, Poulin M, Gil-Rivas V (2002). Nationwide longitudinal study of psychological responses to September 11. JAMA 288: 1235-1244.

Thabet A, Vostanis P (1999). Post-traumatic stress reaction in children of war. J Child Psychol Psychiat Allied Disciplines 40: 385-391.

Wee DF, Mills DM, Koehler G (1999). The effects of Critical Incident Stress Debriefing (CISD) on emergency medical services personnel following the Los Angeles civil disturbance. Int J Emerg Ment Health 1: 33-37.

Weinstein ND (1989). Optimistic biases about personal risks. Science 24: 1232-1233.

Weisaeth L (1994). Preventive psychosocial intervention after disaster. In: Hobfoll SE, deVries MW (eds). Extreme Stress and Communities: Impact and Intervention. Kluwer Academic Publishers: Dordrecht, The Netherlands.

Yehuda R. (1999). Risk Factors for Posttraumatic Stress Disorder, Progress in Psychiatry Series. American Psychiatric Association Inc.: Washington, DC.

Yehuda R (2002). Post-traumatic stress disorder. N Engl J Med 346: 108-114.

Yehuda R, Schmeidler J, Wainberg M, Binder-Brynes K, Duvdevani $\mathrm{T}$ (1998). Vulnerability to posttraumatic stress disorder in adult offspring of Holocaust survivors. Am J Psychiatry 155: 1163-1171.

Zimbardo PG, Ebbesen EB, Maslach C (1977). Influencing Attitudes and Changing Behavior. Addison-Wesley: Reading, MA. 